\title{
Implementation WiMAX Stations
}

\author{
Sucre Ramirez, $\mathrm{Msc}^{1}$, Freddy Jimenez, $\mathrm{Dr}^{1}$, Willian Camilo, $\mathrm{Dr}^{1}$, Eddy Alcantara, $\mathrm{Msc}^{1}$ \\ ${ }^{1}$ UNAPEC, Dominican Republic, sramirez@adm.unapec.edu.do, fjimenez@adm.unapec.edu.do, \\ wcamilo@unapec.edu.do,ealcantara@adm.unapec.edu.do.
}

\begin{abstract}
Technology is growing more and more as the years pass. Most controversial issues in technology are those that have to do with wireless technology, because all the features and diversity of applications that this tech give to us. This article deals with Worldwide Interoperability for Microwave Access (WiMAX). In this paper, we will develop important issues related to this technology, issues that should be common knowledge for students of information technology. Also the paper describes a Case Study about the Implementation of WiMAX to connect ITLA with ITLASantiago.
\end{abstract}

Keywords - WiMAX, Network, Station, LOS, NLOS and WBA.

Digital Object Identifier (DOI): http://dx.doi.org/10.18687/LACCEI2015.1.1.124

ISBN: 13 978-0-9822896-8-6

ISSN: $2414-6668$

$1^{\text {th }}$ LACCEI Annual International Conference: “Engineering Education Facing the Grand Challenges, What Are We Doing?” July 29-31, 2015, Santo Domingo, Dominican Republic ISBN: 13 978-0-9822896-8-6

ISSN: $2414-6668$

DOI: http://dx.doi.org/10.18687/LACCEI2015.1.1.124 


\title{
Implementation WiMAX Stations
}

\author{
Sucre Ramirez, Msc ${ }^{1}$, Freddy Jimenez, Dr ${ }^{2}$, Willian Camilo, $\mathrm{Dr}^{3}$, Eddy Alcantara, Msc ${ }^{4}$ \\ ${ }^{1}$ UNAPEC, Dominican Republic, sramirez@adm.unapec.edu.do, fjimenez@adm.unapec.edu.do, \\ wcamilo@unapec.edu.do, ealcantara@adm.unapec.edu.do.
}

\begin{abstract}
Technology is growing more and more as the years pass. Most controversial issues in technology are those that have to do with wireless technology, because all the features and diversity of applications that this tech give to us. This article deals with Worldwide Interoperability for Microwave Access (WiMAX). In this paper, we will develop important issues related to this technology, issues that should be common knowledge for students of information technology. Also the paper describes a Case Study about the Implementation of WiMAX to connect ITLA with ITLA-Santiago.
\end{abstract}

Keywords - WiMAX, Network, Station, LOS, NLOS and $W B A$.

\section{INTRODUCTION}

Every day technologies give us more benefits, better prices, better performance and quality. Companies, associations and technological communities are working to develop merging technologies, which offer great prospects for the future. This is the case of WiMAX, a long-range wireless technology, supported by the WiMAX forum. This organization is responsible for accelerating the adoption, development, and expansion of WiMAX technology around the world. This organization also certifies and promotes the compatibility and interoperability of wireless products based on the 802.16 standard

The word WiMAX is an acronym for "Worldwide Interoperability for Microwave Access", It is a broadband FWA system with the goal of delivering "last mile" fixed, nomadic, portable and mobile wireless connections on a metropolitan scale. It has been designed for pointto multipoint operation, between one base station (BS) and several subscriber stations (SS). It provides specifications for both fixed Line of sight (LOS) communication in the range of $10-66 \mathrm{GHz}$ (IEEE 802.16c), and fixed, portable, non-LOS communication in the range of $2-11 \mathrm{GHz}$ (IEEE 802.16a \& IEEE 802.16d).

WiMAX is not truly new; rather, it is unique because it was a bottom-up design to deliver maximum throughput to maximum distance while offering 99.999 percent reliability. The IEEE 802.16 standard specifies the Physical (PHY) Layer and Medium Access Control (MAC) layer for BWA within MAN.

In this paper we will develop the technical and characteristics that make WiMAX technology better in certain environments for its implementation. We will focus in Fixed WiMAX because there is a case study in this paper based in that type of WiMAX.

\section{Wireless Broadband}

The term wireless broadband generally refers to high-speed data transmissions occurring within an infrastructure of more or less fixed points, including both stationary subscriber terminals and service provider base stations. Wireless broadband refers to technologies that use point-to-point or point-to-multipoint microwave in various frequencies between 2.5 and $43 \mathrm{GHz}$ to transmit signals between hub sites and an end-user receiver. While on the network layer, they are suitable for both access and backbone infrastructure, it is in the access network where wireless broadband technology is proliferating. As a consequence, the terms "wireless broadband" and "wireless broadband access" are used interchangeably.

The non line-of-sight (NLOS) technologies provide advantages in terms of ease of deployment and wider network coverage. WiMAX counts with this advantage. While many technologies currently available for fixed broadband wireless can only provide line of sight coverage, the technology behind WiMAX has been optimized to provide excellent non line of sight coverage. The Figure-1 shows network types available.

WiMAX advanced technology provides the best of both worlds: Large coverage distances of up to 50 kilometers under LOS conditions and typical cell radii of up to 8 kilometers under NLOS conditions.

$13^{\text {th }}$ LACCEI Annual International Conference: “Engineering Education Facing the Grand Challenges, What Are We Doing?” 


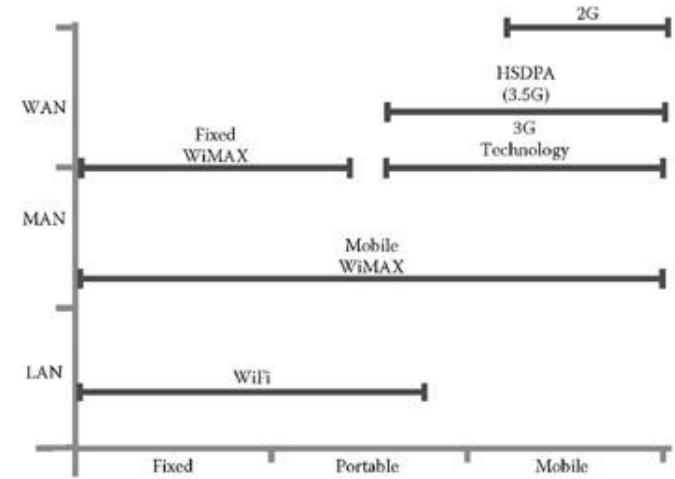

Figure 1 - Types of Wireless Broadband

\section{What is WiMAX?}

WiMAX, Worldwide Interoperability for Microwave Access, is the latest wireless broadband technology which is designed to deliver WiFi type connectivity over a much greater range and thereby compete as a point-to-multipoint lastmile broadband wireless access solution. A wireless technology optimized for the delivery of IP centric services over a wide area.

WiMAX is an IEEE standard defines by the 802.16, a wireless network standard about interoperability of products based in IEEE 802.16 standard. The IEEE 802.16 standard address two types of usage models: A Fixed Usage Model or IEEE 802.16-2004 and a Portable Usage Model or 802.16-2005. The Figure-2 shows the WiMAX forum logo, entity that is allowed to regulate these standards.

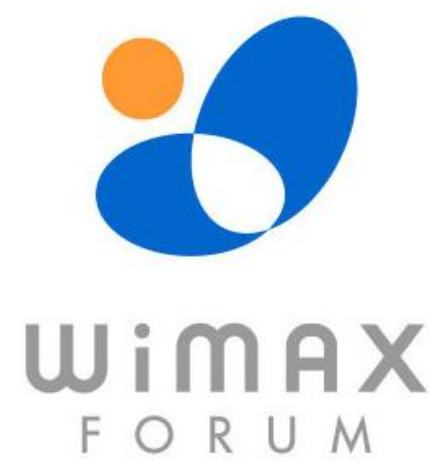

Figure 2 - WiMAX Forum Logo
In other countries IEEE 802.16 standard have adopted other names, for example; In South Korea 802.16e standard is named WiBro, and while in Europe it is named HIPERMAN (High Performance Radio Metropolitan Area Network). It can be define also as a wireless MAN technology that provides broadband wireless connectivity to fixed, portable and nomadic users. These powerful OFDM and NLOS technologies can potentially be used to provide backhaul to cellular networks, 802.11 hotspots and WLANs to the Internet, provide campus connectivity or significantly enhance the performance of $\mathrm{WiFi}$ hotspots by increasing the throughput in the backhaul network and by making it easier and more economical to deploy WiFi access points.

WiMAX Applications

- WiMAX as broadband internet access.

- WiMAX as landline telephone bypass.

- WiMAX as cable or satellite TV bypass.

- WiMAX as mobile data and cell phones bypass.

IEEE 802.16, which is a MAN wireless architecture, currently offers two use cases and soon there will be a third means of interconnection. The first two methods are fixed backhaul and cellular like system. The third architecture is meshing interconnection.

The typical deployment scenarios for WiMAX systems are: Backhaul: Point-to-Point antennas are used to connect BSs located across long distance. Backhaul refers to the connection from an access point or base station back to a central office facility. The Figure-3 shows a pointto-point Fixed WiMAX Backhaul connection. Last Mile: Residential and Business subscribers are connected to the Base Stations using Point-toMultipoint antennas.

Large Area Coverage Access: WiMAX also offers broadband connectivity in larger areas (hot zones). Wi-Fi and WiMAX offer complementary solutions with Wi-Fi being suitable for short range and indoor connections and WiMAX being suitable for ling range outdoor connections.

$13^{\text {th }}$ LACCEI Annual International Conference: "Engineering Education Facing the Grand Challenges, What Are We Doing?"

July 29-31, 2015, Santo Domingo, Dominican Republic 


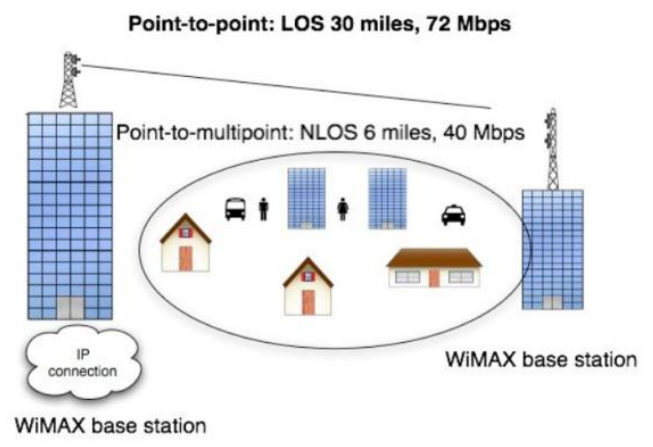

Figure 3 - Fixed WiMAX Point-to-Point

The following table, Table-1, contains a summary if WiMAX Applications and the bandwidth that each application will use in the WiMAX network:

\begin{tabular}{|l|l|l|l|}
\hline Description & $\begin{array}{l}\text { Real } \\
\text { Time? }\end{array}$ & App Type & Bandwidth \\
\hline $\begin{array}{l}\text { VoIP and } \\
\text { Video } \\
\text { Conferencing }\end{array}$ & Yes & $\begin{array}{l}\text { VoIP } \\
\text { Videophone }\end{array}$ & 4-64Kbps \\
\hline $\begin{array}{l}\text { Interactive } \\
\text { Gaming }\end{array}$ & Yes & $\begin{array}{l}\text { Interactive } \\
\text { Gaming }\end{array}$ & $50-85 \mathrm{Kbs}$ \\
\hline $\begin{array}{l}\text { Streaming } \\
\text { Media }\end{array}$ & Yes & $\begin{array}{l}\text { Music, } \\
\text { Video } \\
\text { Clips, } \\
\text { Speech }\end{array}$ & $5-384 \mathrm{Kbps}$ \\
\hline $\begin{array}{l}\text { Movies } \\
\text { Streaming }\end{array}$ & Yes & $\begin{array}{l}\text { Streaming } \\
\text { Media }\end{array}$ & $>2 \mathrm{Mbps}$ \\
\hline $\begin{array}{l}\text { Information } \\
\text { Technology }\end{array}$ & No & $\begin{array}{l}\text { Instant } \\
\text { Messaging } \\
\text { Web } \\
\text { Browsing } \\
\text { Email }\end{array}$ & $\begin{array}{l}<250 \\
\text { byte/messages } \\
>500 \mathrm{Kbps} \\
>500 \mathrm{Kbps}\end{array}$ \\
\hline $\begin{array}{l}\text { Download of } \\
\text { Media } \\
\text { Content, } \\
\text { including } \\
\text { store and } \\
\text { forward }\end{array}$ & No & $\begin{array}{l}\text { Movie } \\
\text { download } \\
\text { Bulk data } \\
\text { Peer to Peer }\end{array}$ & $>1 \mathrm{Mbps}$ \\
\hline
\end{tabular}

Table 1 - WiMAX Applications and BW

System Performance. WiMAX offers high data rate and extended coverage. A maximum of $75 \mathrm{Mbps}$ bandwidth is achievable with a $20 \mathrm{MHz}$ channel under best channel conditions. However, the maximum bandwidth is reduced in the areas where regulators allow only narrower channels.
The theoretical coverage radius is about 30 miles under optimal conditions and with a reduced data rate. At extremely long range, the data rate drops to $1.5 \mathrm{Mbps}$. The typical coverage with indoor Customer Premises Equipment (CPE) is about 5 $\mathrm{Km}$ and with a $\mathrm{CPE}$ connected to an external antenna (LOS), it is around $15 \mathrm{~km}$.

Determining Basic Network Architecture. The basic network architectures are point-to-point, point-to-consecutive-point, point-to-multipoint, and mesh. In this paper we will focus in point-topoint and point-to-multipoint network architectures. To implement network architecture we have to know the requirements of the implementation because each network has different transmissions bands. Transmissions in the highest band $59 \mathrm{GHz}$ to $64 \mathrm{GHz}$ can never be point-to-multipoint or mesh architecture, but a point-to-point connection does. Point-tomultipoint is encountered below the band of $3 \mathrm{GHz}$.

A point-to-multipoint architecture allows the network operator to reach the most subscribers at the lowest cost. While point-to-point provides a directional and unique connection between transmitter and receiver, do not permit any-to-any connectivity. A point-to-consecutive-point is a point to point network in which the signal path returns to its origin point and forms a closed loop. The Figure- 3 and Figure- 4 shows some examples about WiMAX network architectures.

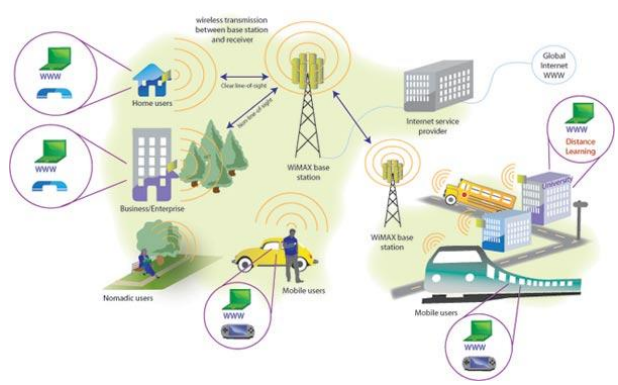

Figure 4 - WiMAX Scheme

Fixed WiMAX is based in 802.16-2004 standards and it provides non-line-of-sight from a base station to a subscriber station, this last one known as customer premise equipment (CPE). Its air interface is based on OFDM (Orthogonal frequency Division Multiplexing) and the access between multiple users in a sector is managed by

$13^{\text {th }}$ LACCEI Annual International Conference: "Engineering Education Facing the Grand Challenges, What Are We Doing?"

July 29-31, 2015, Santo Domingo, Dominican Republic 
TDMA (Time Division Multiple Access). Fixed WiMAX works in many flavors called profiles. They are listed below:

- $3.5 \mathrm{MHz}$ TDD \& FDD in the $3.5 \mathrm{GHz}$ band

- $10 \mathrm{MHz}$ TDD channel in the $5.8 \mathrm{GHZ}$ band

Mobile WiMAX is an extension of Fixed one based in a new standard for mobility, 802.16e2005 standard. This flavor of WiMAX enables cell phone-like applications on much larger scale.

IEEE 802.16 Standards

\begin{tabular}{|l|l|}
\hline $\begin{array}{l}\text { Standard or } \\
\text { Amendments }\end{array}$ & $\begin{array}{l}\text { The basic 802.16 standard. It was } \\
\text { released in 2001. It provided for } \\
\text { basic high data links at } \\
\text { frequencies between 11 and 60 } \\
\text { GHz. }\end{array}$ \\
\hline $802.16 \mathrm{~d}$ & $\begin{array}{l}\text { Also known as 802.16-2004 by } \\
\text { the fact that it was released in } \\
2004)\end{array}$ \\
$\begin{array}{l}\text { 2004. It is a major revision of the } \\
802.16 \text { standard. This standard } \\
\text { provide a number of fixes and } \\
\text { improvements to 802.16a } \\
\text { including the use of 256 carrier } \\
\text { OFDM. Profiles for compliance } \\
\text { testing are also providing, and the } \\
\text { standard is aligned with the ETSI } \\
\text { HiperMAN standard to allow for } \\
\text { global deployment. The standard } \\
\text { only addresses fixed operation. }\end{array}$ \\
$\begin{array}{l}\text { Al known as 802.16-2005 by the } \\
\text { fact of its release date. It is used } \\
\text { for nomadic and mobile } \\
\text { communication. With lower data } \\
\text { rates of 15 Mbps against to 70 } \\
\text { Mbps of 802.16d, it enabled full } \\
\text { nomadic and mobile use } \\
\text { including handover. }\end{array}$ \\
\hline $802.16-$
\end{tabular}

Table 2 - IEEE 802.16 Standards Description

OFDM (orthogonal frequency division multiplex) is a modulation that makes reason to WiMAX offers links of high speed and features extras leading the technology to be one of the best in the market. These are known as the resistance to fade in multi-trajectories and noise in space.

$13^{\text {th }}$ LACCEI Annual International Conference: "Engineering Education Facing the Grand Challenges, What Are We Doing?"

July 29-31, 2015, Santo Domingo, Dominican Republic

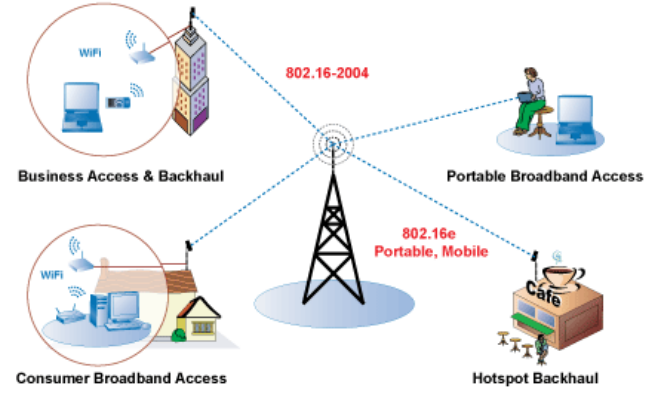

Figure 5 - WiMAX Applications

The so high speeds that offer WiMAX thanks to use the OFDM modulation offers 256 subcarriers of which 192 are used for data, 8 are pilots and 56 are null. The subcarriers pilots are used as reference to minimize displacement of frequency and phase. Finally the 56 null subcarriers are used to guard the band and the frequency DC, which corresponds to the center frequency of the channel.

These can be implemented in different ways, according to each operator, being the variant of OFDM employed a differentiator of the service offered.

So far has been revised in brief and the concept of OFDM, in the following paragraphs will be approach from the perspective of WiMAX the using of other technologies.

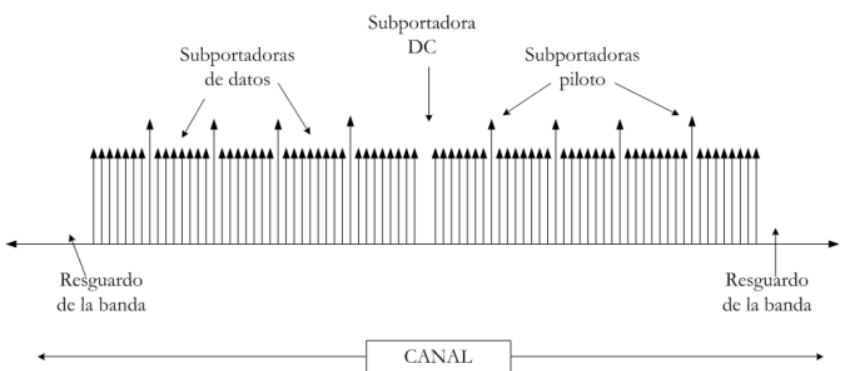

Figure 6-OFDM Signal

OFDMA. WiMAX selected modulation OFDMA for version fixed IEEE 802.16d, in order to ensure NLOS, (transmission line of sight). OFDMA is a technique for multiple accesses based on OFDM, where the user is often of the 10 $\mathrm{KHz}$ and that is assigned to one or more 
orthogonal subcarriers spread over, so that users share the bandwidth. The way the orthogonal subcarriers spread over are allocated depends on the strategy of the operator, as they have direct relationship with the quality of service and the transfer rate.

The first incursion implanted in the cell phones was in the access WiMAX, static and mobile. A benefit of this technique is the easy adaptation to different bandwidths, which resolves problems of assignments multi-frequency blocks.

The benefit of the branch is that allows you to solve one of the current challenges in the wireless systems or multi-trajectory effect. This is the cause of the delays in the spread of the obstacles to a transmitting and receiving, which the same signal reaches at different stages of time. In a comparison between networks CDMA and OFDM the difference may be in the order of 100 microseconds less.

One of the main features which provides OFDM, and which now enjoy systems WiMAX, is the use of advanced signal processing, such as the MIMO. In MIMO, the system takes the fact that the signal received in an antenna can be quite different from the received signal of a second antenna. High population in places where it is common to have many of the multi-trajectories problems it takes to another signal transmission of each antenna to the same frequency.

WiMAX and IP. The protocol IP (Internet Protocol) is one of the great advantages that use IP to work efficiently. To be a protocol that is not geared to connection provides a simpler structure and it takes advantage of better way because systems offer Quality of Service (QoS).

This is why for that WiMAX being a technology of extremes to such extremes that offers high data rates and extensive coverage in the area WiMAX should you go through border of the IP protocol. This technique is supported by WiMAX.

Features:

- Coverage from end to end. Necessary for WiMAX since it is not exclusive for use with the Internet, it uses in networks that are dedicated which have no relationship to the Internet.

- Offers Quality of Service (QoS) for connection reliability.

13 $^{\text {th }}$ LACCEI Annual International Conference: "Engineering Education Facing the Grand Challenges, What Are We Doing?"

July 29-31, 2015, Santo Domingo, Dominican Republic
WiMAX and AAS

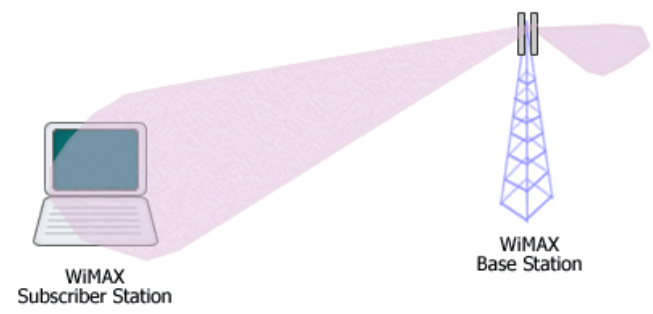

Figura 7 - Base Station with AAS

Adaptive Antenna System (AAS) focus its transmit energy to the direction of a receiver. While receiving, it can focus to the direction of the transmitting device. The technique used in AAS is known as beam forming. It works by adjusting the width and the angle of the antenna radiation pattern.

Combined with multiple antennas in the Base Station (BS), AAS can be used to serve multiple Subscriber Stations (SSs) with higher throughput. A technique known as SDMA (Space Division Multiple Access) is employed here where multiple SSs that are separated (in space) can transmit and receive at the same time over the same subchannel.

AAS also eliminates interference to and from other SSs and other sources by steering the nulls to the direction of interferers. AAS is an optional feature in WiMAX and not included in WiMAX certification. But due to its effectiveness in improving performance and coverage especially in Mobile WiMAX case, many vendors integrate AAS capability into their products.

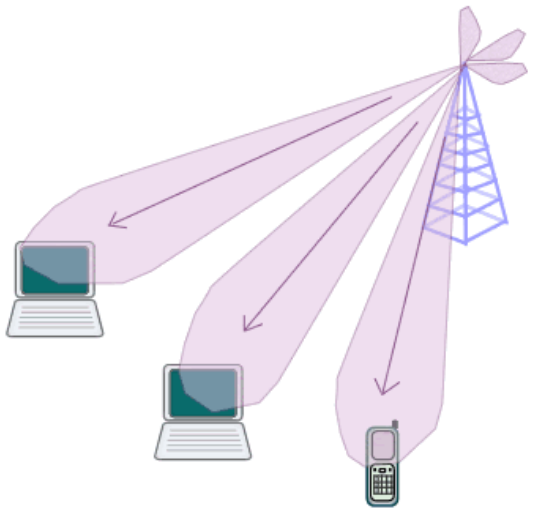

Figura 8 - Base Station with Multiple ASS 
WiMAX and AES. Encryption is a mechanism that protects data confidentiality and integrity. Encryption takes plaintext (i.e., your data) and mixes that information using a complex mathematical algorithm to produce cipher text. The cipher text is then transmitted over the wireless network and cannot be understood by an eavesdropper.

WiMAX uses the Advanced Encryption Standard (AES) to produce cipher text. AES takes an encryption key and a counter as input to produce a bit stream. The bit stream is then exclusive OR'd with the plaintext to produce the cipher text.

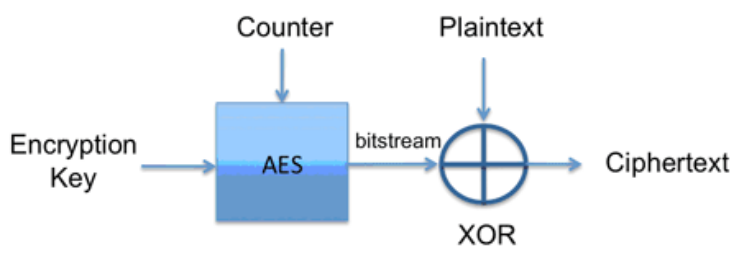

Figure 9-AES Scheme

The receiver of the cipher text simply reverses the process to recover the plaintext. In order for this process to work, the transmitter and the receiver must share the same encryption key.

WiMAX Security. The word security implies a broad and complex subject. This section will provide only a brief introduction to security, introducing some terminology and security mechanisms relate especially with WiMAX.The basic requirements to have well-designed security architecture for a wireless communication system is: Privacy, data integrity, authentication, authorization and access control.

Security is handled at various layers in the IP Stack, for example; at the link layer we have AES encryption, while at the network layer we have Firewall, IPSec and RADIUS Servers. In WiMAX security is implemented in the MAC Layer.

WiMAX is a technology that from the beginning was created to provide a robust security inherent. This standard provides methods for ensuring user data privacy and preventing unauthorized access.
User data is encrypted using AES (Advanced Encryption Standard) and 3DES (Triple Data Encryption Standard). The authentication framework (subscriber stations and users authentication) is based on EAP, which supports a variety of credentials like usernames and passwords, digital certificates, and smart cards. WiMAX terminal devices come with built-in X.509 digital certificates, and this one contain the public key and MAC addresses of those terminal devices.

WiMAX also use PKM a client-server protocol, specially the version 2 of this protocol. With PKMv2 the key exchanges process between the Mobile Station and the Base Station is secured. The following table describes the security methods for each WiMAX Flavor:

\begin{tabular}{|c|c|}
\hline $\begin{array}{l}\text { WiMAX } \\
\text { Flavors }\end{array}$ & $y$ \\
\hline $\begin{array}{l}\text { Fixed } \\
\text { WiMAX or } \\
802.16-2004\end{array}$ & $\begin{array}{l}\text { X.509 certificates for } \\
\text { authentication. } \\
\text { 56-bit DES (Digital Encryption } \\
\text { System) for encryption. }\end{array}$ \\
\hline $\begin{array}{l}\text { Mobile } \\
\text { WiMAX or } \\
802.16 \mathrm{e}-2005\end{array}$ & $\begin{array}{l}\text { EAP for authentication } \\
\text { AES (Advanced Encryption } \\
\text { System) for encryption. }\end{array}$ \\
\hline Both & $\begin{array}{l}\text { Use PKM (Privacy Key } \\
\text { Management) for authentication } \\
\text { between base stations and } \\
\text { subscribers stations. }\end{array}$ \\
\hline
\end{tabular}

Table 3 - WiMAX Security

WiMAX Network Architecture. To developed WiMAX network systems architecture there are important design principles to follow and those are:

- Functional decomposition

- Deployment modularity and flexibility

- Support for variety or usage models

- Decoupling of access and connectivity services

- Support for a variety of business models

- Extensive use of IETF protocols

- Support for access to necessary operator services

WiMAX Forum's Network Working Group (NWG) is the responsible to develop of the end to

$13^{\text {th }}$ LACCEI Annual International Conference: "Engineering Education Facing the Grand Challenges, What Are We Doing?"

July 29-31, 2015, Santo Domingo, Dominican Republic 
end network connectivity requirements, protocols and architecture for 802.116 standards. This entity has developed a network reference model that will serve as architecture framework for developing WiMAX and ensure interoperability between equipments and operators.

The WiMAX network is logically divided into three components:

1. ASN (Access Service Network)

2. CSN (Connectivity Service Network)

3. MS (Mobile Stations)/SS (Subscriber Station)

Mobile Stations (MS)/ Subscriber Stations (SS) are used by the end users to access the network. The Access Service Network or ASN comprehend one or more Base Stations (BS) and one or more ASN Gateways that form the radio access network at the Edge. And the third component, the Connectivity Service Network or CSN supplies IP connectivity and all IP core network roles.

These WiMAX network architectures work with three separate business entities. These are:

1. NAP (Network Access Provider)

2. NSP (Network Service Provider)

3. ASP (Application Service Provider)

The Network Access Provider or NAP owns and operates the ASN; The Network Service Provider or NSP provides IP connectivity and WiMAX services to subscribers, using the ASN infrastructure supplied by one or more NAPs; and Application Service Provider or ASP which provides services such as multimedia applications and corporate Virtual Private Networks (VPN).

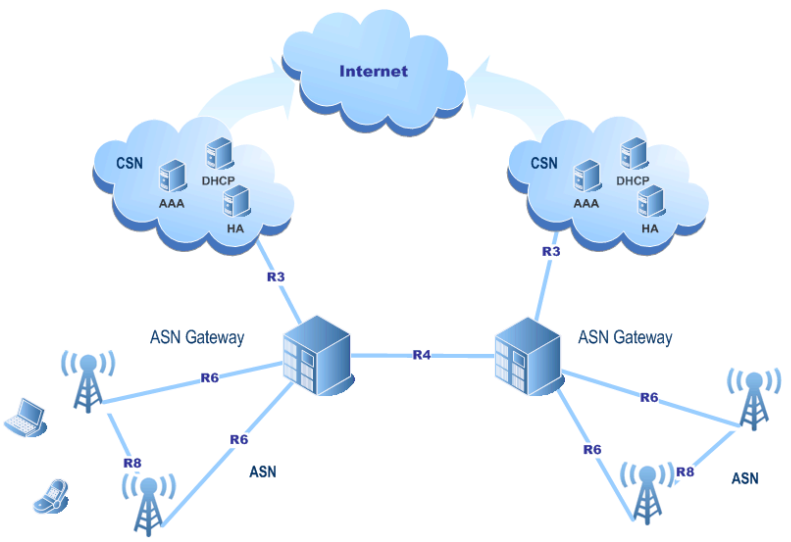

Figure 10 - WiMAX Architecture
Base Station (BS). The base station provides the interface between the mobile user and the WiMAX network; in other words, The BS provides the air interfaces to the MS. The base station works within radio equipment and a base station link to the backbone network.

Access Service Network Gateway (ASNGW). The ASN Gateway provides a layer 2 traffic aggregation in the ASN. It performs functions of connectivity and mobility management. Also it supplies inter-service provider network limits through processing of subscriber control data traffic. Other functions of ASN Gateway are: caching of subscriber profiles and encryption keys, AAA client functionality, QoS and policy enforcement.

Core Services Networks (CSN). The main functions of a Core Service Network are: Transport, Authentication and Switching. The CSN represents the core network in WiMAX which provides connectivity to the Internet, ASP, other public networks, and corporate networks. The CSN is owned by the Network Service Provider (NSP) and the following are functions of it:

- AAA servers which supports authentication for devices and users.

- IP Address Management.

- Roaming between different NSPs.

- Mobility and Roaming within ASNs.

- Gateways and internetworking with other networks such as PSTN and 3GPP.

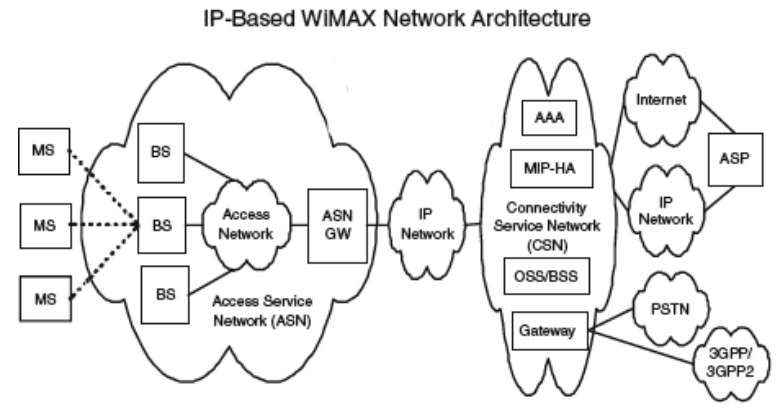

Figure 11 - IP Based WiMAX Network Architecture

Network Discovery and Selection. It is theorized that a Mobile Station (MS)/Subscriber Station (SS) will operate in conditions in which multiple networks will be available to connect to

13 $^{\text {th }}$ LACCEI Annual International Conference: "Engineering Education Facing the Grand Challenges, What Are We Doing?"

July 29-31, 2015, Santo Domingo, Dominican Republic 
and multiple service providers will offer services over those available networks. WiMAX standard offers a solution to facilitate this operation and allows the MS/SS to discover and select the network either manually and automatic.

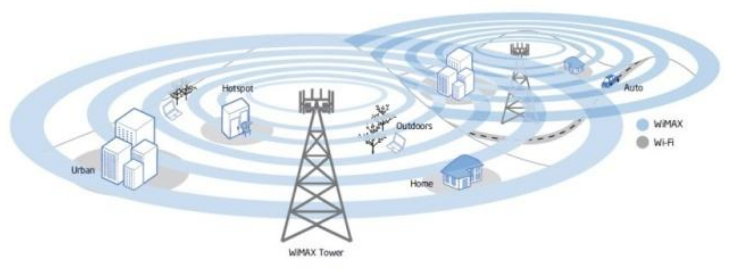

Figure 12- Wi-Fi \& WiMAX

- WiMAX uses licensed and unlicensed spectrum to deliver connection to a network, in most cases the internet. In the other hand, Wi-Fi uses unlicensed spectrum to deliver access to a local network.

- WiMAX runs a connection oriented MAC, but Wi-Fi runs on the CSMA/CA protocol which is connection less and connection based

The following table we can see a comparison about this two wireless technologies:

\begin{tabular}{|c|c|c|c|}
\hline & $\begin{array}{l}\text { Wi-Fi } \\
802.11\end{array}$ & $\begin{array}{l}\text { WiMAX } \\
802.16\end{array}$ & $\begin{array}{l}\text { Technical } \\
\text { Difference }\end{array}$ \\
\hline Range & $\begin{array}{l}\text { Up to } 100 \\
\text { meters }\end{array}$ & $\begin{array}{l}\text { Up to } 40 \\
\text { Kilometers }\end{array}$ & $\begin{array}{l}802.16 \\
\text { MAC } \\
\text { tolerate } \\
\text { greater } \\
\text { multipath } \\
\text { delay } \\
\text { spread }\end{array}$ \\
\hline Coverage & $\begin{array}{l}\text { Optimized } \\
\text { for indoor } \\
\text { performance }\end{array}$ & $\begin{array}{l}\text { Optimized } \\
\text { for Outdoor } \\
\text { NLOS } \\
\text { performance }\end{array}$ & $\begin{array}{l}802.16- \\
256 \text { OFDM } \\
\text { Vs. } 64 \\
\text { OFDM }\end{array}$ \\
\hline Scalability & $\begin{array}{l}\text { Channel } \\
\text { Bandwidth } \\
\text { is Fix } \\
20 \mathrm{Mhz}\end{array}$ & $\begin{array}{l}\text { Channel } \\
\text { Bandwidth } \\
\text { is flexible } \\
\text { between } \\
1,5 \mathrm{Mhz} \text { and } \\
20 \mathrm{Mhz} \text {. }\end{array}$ & $\begin{array}{l}\text { non- } \\
\text { overlapping } \\
\text { channel for } \\
802.11 \mathrm{~b} \\
5 \text { non- } \\
\text { overlapping } \\
\text { channel for } \\
802.11 \mathrm{a} \\
802.16 \text { : } \\
\text { limited by }\end{array}$ \\
\hline
\end{tabular}

$\mathbf{1 3}^{\text {th }}$ LACCEI Annual International Conference: "Engineering Education Facing the Grand Challenges, What Are We Doing?"

July 29-31, 2015, Santo Domingo, Dominican Republic

\begin{tabular}{|l|l|l|l|}
\hline & & & $\begin{array}{l}\text { available } \\
\text { spectrum }\end{array}$ \\
\hline Bit Rate & $\begin{array}{l}\text { Up to } \\
54 \mathrm{Mbps} \text { in } \\
20 \mathrm{Mhz} \\
\text { Channel }\end{array}$ & $\begin{array}{l}\text { Up to } \\
100 \mathrm{Mbps} \text { in } \\
20 \mathrm{Mhz} \\
\text { Channel }\end{array}$ & $\begin{array}{l}802.16 \\
\text { MAC } \\
\text { efficiency } \\
\text { constant } \\
\text { with PHY } \\
\text { rate } \\
\text { increase }\end{array}$ \\
\hline QoS & $\begin{array}{l}\text { Qos in } \\
802.11 \mathrm{e} \\
\text { standard }\end{array}$ & $\begin{array}{l}\text { Qos built } \\
\text { into MAC } \\
\text { Differentiate } \\
\text { service } \\
\text { levels } \\
\text { voice/video }\end{array}$ & $\begin{array}{l}802 . \\
11: \text { CSMA } \\
802.16: \\
\text { grant } \\
\text { request } \\
\text { MAC }\end{array}$ \\
\hline
\end{tabular}

Table 4- Wi-Fi \& WiMAX Comparison

\section{Case Study}

WiMAX is a new wireless technology that has been applied in all over the world. For this reason, we had our choice of WiMAX to know much better about this technology and offer another technology implementation to the university.

After the explanation about WiMAX described in the previous chapters, we will apply this technology to connect ITLA Las Americas with ITLA Santiago, with a point-to-point Fixed WiMAX network connection.

This Fixed Wireless Access (FWA) is a solution for last mile access. In this system both the sender and receiver are both stationary that is why it is called Fixed. The Point-to-Point Fixed WiMAX connection consists of two base stations with the communication statically configured for a link between these two base stations.

This implementation is also known as Fixed WiMAX Backhaul because the connection will comprise the intermediate links between the core network or backbone, which one is in ITLA Las Americas, and a small sub network at the edge that will be ITLA Santiago.

Geographic Area. Below we have a representative map showing the distance that which is ITLA Santiago from ITLA Las Americas. We can see the range that we have to cover to make a connection of these two points by WiMAX. The average distance between ITLA Las 
Americas and ITLA Santiago is about 180 kilometers.

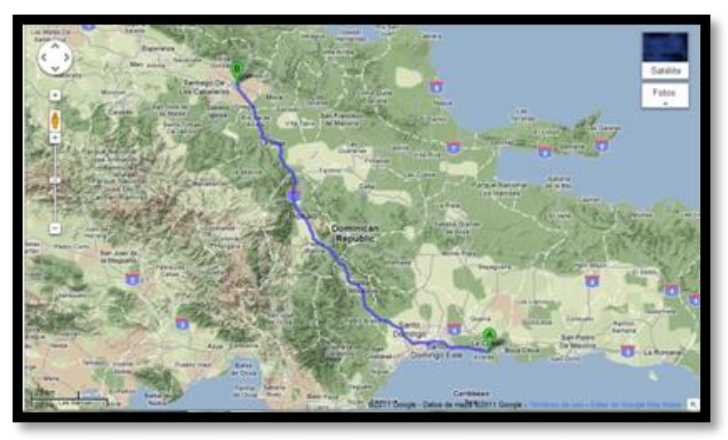

Figure 13 - Distance ITLA-ITLA Santiago

Topology and Network Description. For covering the average distance of $180 \mathrm{~km}$ we will use two Base Stations and two WiMAX Repeaters between them. The WiMAX network to implement is going to be a WiMAX Backhaul (Figure-9). The Base Station that will provide internet connectivity to ITLA Santiago will be connected to the Wired Network in that location, so that the internet will be providing ITLA Campus Santiago by Wi-Fi.

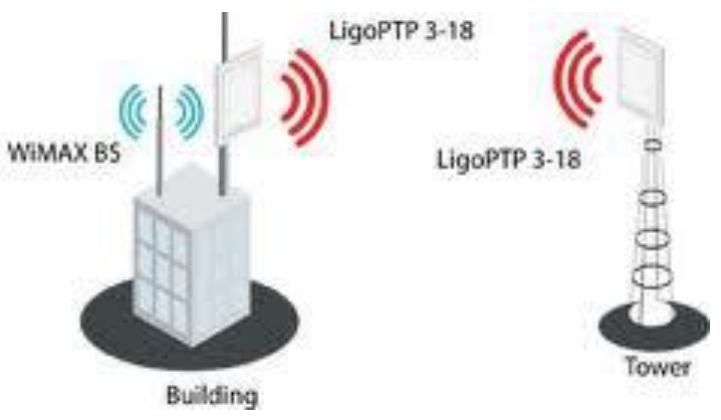

Figure 14- Fixed WiMAX

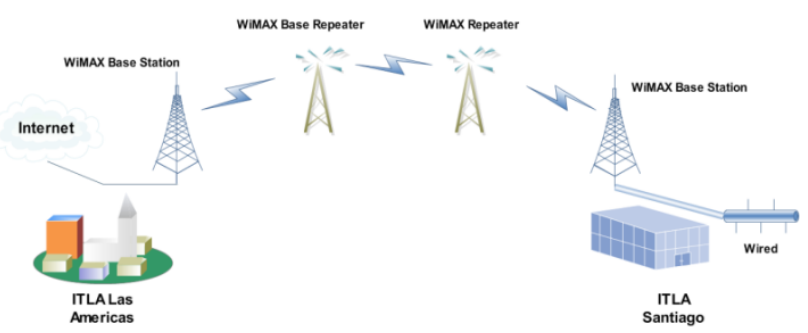

Figure 15- ITLA WiMAX Scheme
This connection is going to be LOS (Line-of Sight), and will cover 45 kilometers. The connection will deliver a minimum of $40 \mathrm{Mps}$ and a maximum of 72 Mbps. Security will be implemented in the Base Stations. The Authentication to be used will be x.509 certificates within 56-bit DES Encryption. For authentication between base stations and subscriber station will be used Privacy Key Management (PKM).

The antennas or Radio Towers will be 60 meters up from the earth. Both of the base station will work with a WiMAX radio (Figure-11), and this radio contains the transmitter and receiver. The WiMAX radio will be protected from extremes heat cold and humidity. The antenna will be connected to the WiMAX radio by a cable called pigtail. For the implementation we will keep the pigtail the most shot as possible to avoid lost signal between the radio and the antenna.

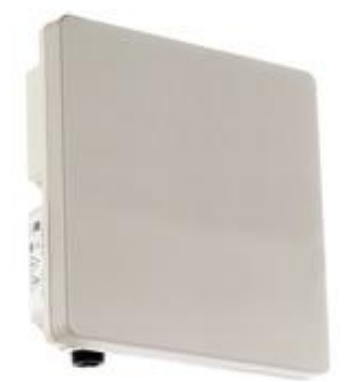

Figure16- WiMAX Radio

The antennas to be used will be Directional, especially Panel antennas or flat panel ones (Figure-12). The Ethernet cable that connects the radio and the antenna will be performed by Power over Ethernet (PoE).

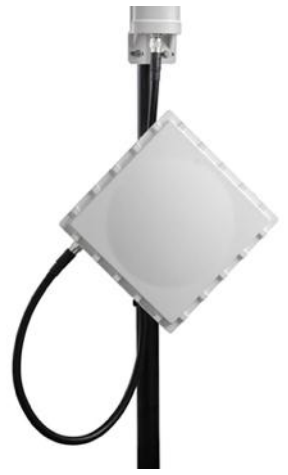

Figure 17- WiMAX Directional Antenna

13 $^{\text {th }}$ LACCEI Annual International Conference: "Engineering Education Facing the Grand Challenges, What Are We Doing?"

July 29-31, 2015, Santo Domingo, Dominican Republic 
A WiMAX CPE receives the services. There will be use an Outdoor CPE (Customer Premise Equipment); the reception is not impeded by walls, RF blocking glass or steel in the building's walls. Using an Outdoor CPE (Figure-13) the reception via LOS (Line of sight) connection will be maximized. Two WiMAX RF Repeaters will be used between the Base Stations to extend the coverage of the Base, providing broadband coverage to the last mile. The WiMAX RF Repeater will provide better signal quality and cell coverage extension for this Wireless Broadband Service Implementation.

The repeater allows system operators to bypass direct LOS obstacles between the base station and areas with new subscribers, extending coverage beyond the Base Station standard range.

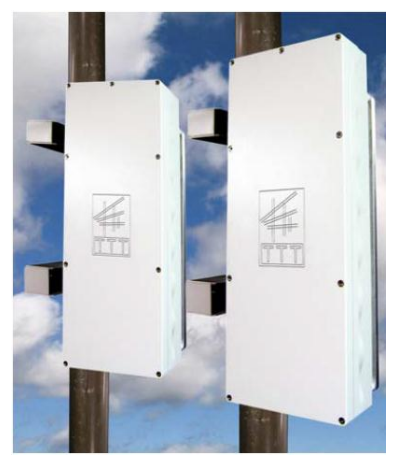

Figure 19- WiMAX RF Repeater

Devices and Accessories to be used. Below will be listed all the Devices and accessories to be used in this implementation. Also we will be showing the prices and final budget of the devices. Before is important to know that we are going to use for this Fixed WiMAX Backhaul network: WiMAX Base Stations, Outdoor CPE, Antennas and Accessories, Pigtail Cable.

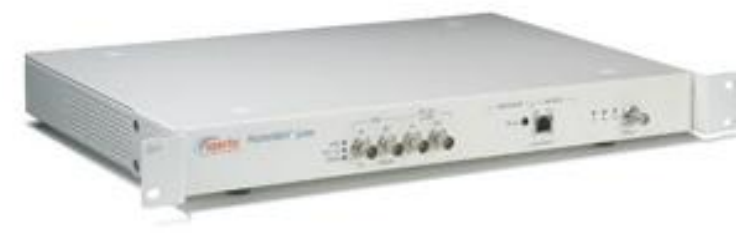

PacketMAX 300 Micro WiMAX Base Station

Figure 20 - Base Station

There will be two base stations of this model, one in each location. We have selected this device because it is a WiMAX Forum certified product, and it is compatible with all PacketMAX outdoor radios.

VistaMAX OSR3500 Outdoor CPE. This device has been choosing because it is also a WiMAX Forum certified product and offers all the technical's capabilities to provide a great network performance.

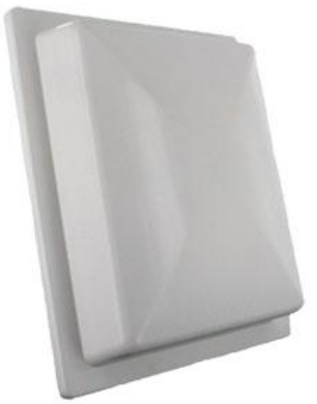

Figure 21 - Outdoor CPE

LigoPTP 4-19/4-N Point-to-Point Bridge Solutions. This point-to-point bridge solution from LigoWave has been choosing because it delivers true TCP throughput up to $40 \mathrm{Mbps}$. It also has an integrate antenna that cover long distances and offers an advanced software mechanism to provide optimal point-to-point connectivity for highthroughput.

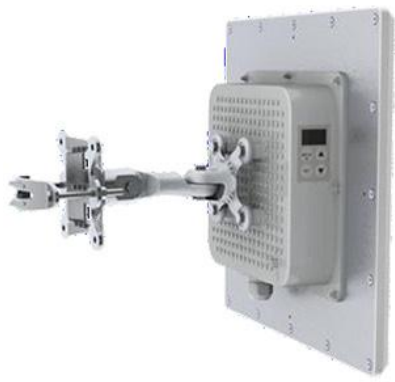

Figure 22- WiMAX Radio LigoPTP 4-19

This solution also works with TDD to optimize the bandwidth use and it supports advanced security protocols to secure the connection.

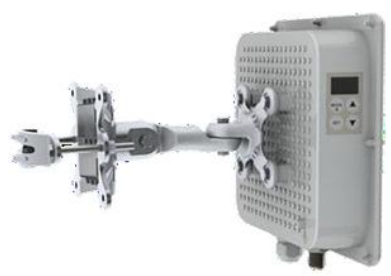

Figure 23- WiMAX Radio LigoPTP 4-N

$13^{\text {th }}$ LACCEI Annual International Conference: "Engineering Education Facing the Grand Challenges, What Are We Doing?"

July 29-31, 2015, Santo Domingo, Dominican Republic 
WiMAX Repeater5.8 and 5.4 GHz Band. This equipment will be provided by Albentina Systems a Europe company that offers Wireless Broadband solutions. Its web site is www.albentia.com. We have chosen this equipment because it is compatible with any WiMAX equipment and it is totally transparent to the Base Station and CPEs connected through the repeater. It has also compact form factor and low power consumption.

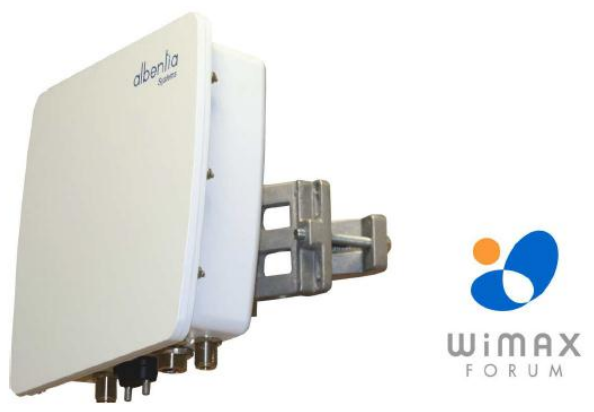

Figure 24 - WiMAX Repeater RF

To see the Data Sheet of this equipment please go through this link:

Budget. Below there is a budget table which contains the equipment to be use with each price and the total of equipment needed.

The prices are in dollars. The dollar rate in Dominican Republic is \$ RD 38.15.

\begin{tabular}{|l|r|r|r|}
\hline Equipment & Amount & Price & \multicolumn{1}{l|}{ Total } \\
\hline $\begin{array}{l}\text { Pigtail Cable } \\
\text { N-type }\end{array}$ & 2 & $\$ 45.00$ & $\$ 90.00$ \\
\hline $\begin{array}{l}\text { WiMAX } \\
\text { Outdoor CPE }\end{array}$ & 1 & $\$ 350.00$ & $\$ 350.00$ \\
\hline $\begin{array}{l}\text { PoE Injector } \\
\text { PS-48V-INT }\end{array}$ & 2 & $\$ 19.95$ & $\$ 39.9$ \\
\hline LigoPTP 4-19 & 2 & $\$ 670.00$ & $\$$ \\
\hline LogoPTP 4-N & 2 & $\$ 625.00$ & $\begin{array}{r}\$ \\
1,250.00\end{array}$ \\
\hline $\begin{array}{l}\text { Wireless } \\
\text { Repeater }\end{array}$ & 2 & $\$$ & $\$$ \\
& & $\begin{array}{r}\text { Grand } \\
\text { Total }\end{array}$ & $\begin{array}{r}\$, 000.00 \\
7\end{array}$ \\
\hline
\end{tabular}

\section{Conclusion}

Learning about the technical aspects about WiMAX and how this new technology, which is on deployment, work enable us to determine a good set of scenarios to run. It also allows us to open our mines to get involve deeply in this wireless technology. WiMAX offers more coverage than Wi-Fi, covering long distances, fact that converts it into a new world to get involved and make new implementation ideas.

A great deal to work in is complement WiMAX and Wi-Fi together, like if they were a hybrid network. This will provide better networks implementations and cost-effective networks coverage.

WiMAX like a technology that promises to deliver high data rates, is so much expensive, and implementing it with $\mathrm{Wi}-\mathrm{Fi}$ can reduce the high price that comprise WiMAX networks implementations.

There is a disadvantage of WiMAX so important to know and keep in mind and is about the very power intensive technology that WiMAX is and the strong electrical support it required. This is a turning point for mobile devices which ones rely on batteries.

WiMAX offers develop and covering area wireless access without the need to implement a proper infrastructure such as cabling and jacking the wireless.

\section{References}

[1] G.S.V. Radha K. Rao \& G. Radhamani, 2007, WiMAX A Wireless Technology Revolution; Auerbach Publications.

[2] Jeffrey G. Andrews, Arunabha Ghosh and Rias Muhamed, 2007, Fundamentals of WiMAX: Understanding Broadband Wireless Networking; Prentice Hall.

[3] Daniel Sweeney, 2004, WiMax Operator's Manual: Building 802.16 Wireless Networks; Apress.

[4] Deepak Pareek, 2006, The Business of WiMAX; Wiley.

[5] Loutfi Nuaymi, 2007, WiMAX: Technology for Broadband Wireless Access; Wiley.

[6] Houda Labiod, Hossam Afifi \& Costantino de Santis, 2010, Wi-Fi(TM), Bluetooth(TM), Zigbee(TM) and WiMax(TM); Springer.

$13^{\text {th }}$ LACCEI Annual International Conference: "Engineering Education Facing the Grand Challenges, What Are We Doing?"

July 29-31, 2015, Santo Domingo, Dominican Republic 
[7] Mustafa Ergen, 2009, 3. Mobile Broadband: Including WiMAX and LTE; Springer.

[8] Yang Xiao, 2007, WiMAX/MobileFi: Advanced Research and Technology; Auerbach Publications.

[9] Yan Zhang, 2009, WiMAX Network Planning and Optimization (Wireless Networks and Mobile Communications); Auerbach Publications.

[10]Frank Ohrtman, 2006, 8. WiMAX in 50 Pages; Monnoz Publishing.

[11]Syed A. Ahson \& Mohammad Ilyas, 2007, 11. WiMAX: Standards and Security; CRC Press.

[12]Kevin Roebuck, 2011, 12 . WiMax 802.16e: High-impact Technology - What You Need to Know: Definitions, Adoptions, Impact, Benefits, Maturity, Vendors; Tebbo.

[13]Savo G. Glisic, 2006, Advanced Wireless Networks 4G Technologies; Wiley.

[14]Regis J. Bates, 2002, Broadband Telecommunications Handbook; McGraw-Hill Professional.
[15]David Tse \& Pramod Viswanath, 2005, Fundamentals of Wireless Communication; Cambridge University Press.

$13^{\text {th }}$ LACCEI Annual International Conference: "Engineering Education Facing the Grand Challenges, What Are We Doing?"

July 29-31, 2015, Santo Domingo, Dominican Republic 
13 $^{\text {th }}$ LACCEI Annual International Conference: "Engineering Education Facing the Grand Challenges, What Are We Doing?" July 29-31, 2015, Santo Domingo, Dominican Republic 